\title{
УДК 621.314-047.58
}

\section{В. В. МИХАЙЛЕНКО ${ }^{1 *}$, С. А. АБДУЛАСВ ${ }^{2}$, В. В. ЕРНСТ ${ }^{3}$, В. В. ЧУПАК ${ }^{4}$}

\author{
${ }^{1 *}$ Каф. «Теоретична електротехніка», Національний технічний університет України «Київський політехнічний \\ інститут», пр-т Перемоги, 37, Київ, Україна, 03056, тел./факс + 38 (098) 31793 74, ел. пошта VladislavMihailenko@i.ua, \\ ORCID 0000-0002-5945-7502 \\ ${ }^{2}$ Каф. «Електричні мережі і системи», Національний технічний університет України «Київський політехнічний \\ інститут», пр-т Перемоги, 37, Київ, Україна, 03056, тел./факс + 38 (098) 985 26 00, ел. пошта seryk15abdulaev@rambler.ru, \\ ORCID 0000-0001-8939-1471 \\ ${ }^{3}$ Каф. «Електричні мережі і системи», Національний технічний університет України «Київський політехнічний \\ інститут», пр-т Перемоги, 37, Київ, Україна, 03056, тел./факс + 38 (050) 90113 94, ел. пошта vasilyernst@mail.ru, \\ ORCID 0000-0002-2922-0918 \\ ${ }^{4}$ Каф. «Технології машинобудування», Національний технічний університет України «Київський політехнічний \\ інститут», пр-т Перемоги, 37, Київ, Україна, 03056, тел./факс + 38 (097) 86806 35, ел. пошта viktorchupak@ukr.net, \\ ORCID 0000-0002-7103-6364

\section{МАТЕМАТИЧНА МОДЕЛЬ НАПІВПРОВІДНИКОВОГО ПЕРЕТВОРЮВАЧА 3 П'ЯТИЗОННИМ РЕГУЛЮВАННЯМ ВИХІДНОЇ НАПРУГИ ТА ЕЛЕКТРОМЕХАНІЧНИМ НАВАНТАЖЕННЯМ}

Мета. Робота спрямована на дослідження виконання аналізу електромагнітних процесів в електричних колах із напівпровідниковими комутаторами. Необхідно розробити нові математичні моделі та визначити функції та алгоритми рівнянь для аналізу усталених та перехідних процесів в електричних колах змінної структури. Також передбачається дослідити математичні моделі з напівпровідниковими комутаторами та ланками, в яких виникають синусоїдні, постійні й імпульсні напруги. Методика. Для досягнення поставленої мети була створена математична модель напівпровідникового перетворювача з електромеханічним навантаженням. Показано, що поява нелінійних елементів суттєво ускладнює задачі розрахунку та дослідження виникаючих у колах електромагнітних процесів. Найбільші ускладнення з'являються у колах змінної структури, в ланках яких виникають синусоїдні, постійні та імпульсні струми під дією відповідних напруг. Результати. Розроблено нові математичні моделі електромагнітних процесів у трифазних електричних колах напівпровідникових перетворювачів із багатоканальним зонним регулюванням фазних напруг (без урахування енергетичних втрат у напівпровідникових комутаторах) для швидкої оцінки впливу параметрів навантаження на рівень та форму вихідної напруги. Наукова новизна. Розвинуто метод багатопараметричних функцій, які входять до алгоритмічних рівнянь аналізу усталених та перехідних процесів у розгалужених електричних колах із напівпровідниковими комутаторами та реактивними елементами, в напрямку врахування особливостей використання фазних напруг мережі електроживлення. Обгрунтовано, що використання методу багатопараметричних модулюючих функцій в електричних колах змінної структури є доцільним, якщо в їх ланках не більше трьох незалежних реактивних елементів. Розроблено нову математичну модель усталених і перехідних процесів в електричних колах напівпровідникових перетворювачів модуляційного типу з багатоканальним зонним використанням фазних напруг трифазної мережі живлення. При цьому втрати електроенергії у комутаторах не враховувались. Така математична модель була розроблена для швидкої оцінки впливу параметрів навантаження на характеристики регульованих синусоїдних та постійних напруг. Практична значимість. Створено нові схемотехнічні рішення напівпровідникових комутаторів із високочастотним широтноімпульсним регулюванням вихідної напруги при зміні параметрів навантаження в широких межах. Це дозволило підвищити швидкодію електротехнологічних систем. Розроблено методики підвищення швидкості регулювання та визначення енергоефективних режимних параметрів напівпровідникових комутаторів електротехнологічних систем. Розроблено нові методики аналізу усталених та перехідних процесів в електричних колах напівпровідникових перетворювачів модуляційного типу з постійними вихідними напругами та з різними видами модулюючих впливів.

Ключові слова: електромагнітні процеси; вихідна напруга; вихідний струм; двигун постійного струму; метод багатопараметричних модулюючих функцій 


\section{Вступ}

Тенденції якісного перетворення електричної енергії, а також успіхи у розвитку напівпровідникової техніки дозволяють використовувати в перетворювальних установках ланку високої частоти з частотою переключення вентилів значно більшою, ніж частота змінної напруги промислової мережі [1-13]. У роботах $[8,4,5,6]$ наведена доцільність використання структур перетворювачів частоти (ПЧ) 3 однократною модуляцією під час побудови систем вторинного електропостачання для комплексів діагностики електромеханічних пристроїв із різноманітним видом вхідної енергії. У цій роботі виконано аналіз аспекту використання тієі ж структури ПЧ для електромеханічних комплексів із широтно-імпульсним регулюванням (ШІР) постійної напруги при п'ятизонному керуванні.

\section{Мета}

Виконання аналізу електромагнітних процесів в електричних колах з напівпровідниковими комутаторами і розробка математичної моделі напівпровідникового перетворювача 3 електромеханічним навантаженням.

\section{Методика}

Узагальнена структурна схема перетворювача наведена на рис. 1. На структурній схемі позначені: $\mathrm{CM} A, \mathrm{CM} B, \mathrm{CM} C$ - силові модулятори (CM) фазних $A, B$ і $C$ відповідно; $\mathrm{BB}$ - високочастотний випрямляч; $\mathrm{H}$ - навантаження; $D$ - двигун постійного струму. Сукупність СМ, підключених до енергетичної мережі паралельно і з'єднаних по виходу послідовно, являє собою ланку високої частоти перетворювача.

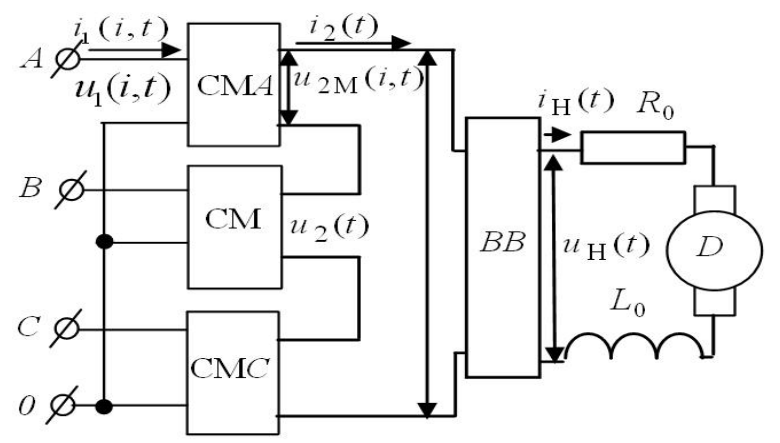

Рис. 1. Структурна схема перетворювача

Fig. 1. Structural diagram of a converter
За результатами порівняльних досліджень техніко-економічних показників різного виду виконавчих елементів слідкуючих систем на основі високомоментних двигунів постійного струму (ДПС) серій $2 П$ та ПВ і трифазних асинхронних двигунів серії 4А, які випускаються промисловістю серійно [4], з'ясовано, що за умови однакових показників за масою та габаритами в діапазоні потужностей від 100 Вт до 500 кВт, у слідкуючих системах доцільніше використовувати ДПС.

Під час складання математичної моделі перетворювача 3 комп'ютерною орієнтацією іiі застосування використаємо метод багатопараметричних модулюючих функцій [8], який передбачає попереднє подання алгоритмічного рівняння перетворювача. При цьому приймемо такі припущення: вхідна енергетична мережа симетрична і ії внутрішній опір дорівнює нулю, транзистори і діоди інверторів випрямленої напруги (IBH) подають як ідеальні ключі, узгоджувальні трансформатори в кожній із зон регулювання вихідної напруги не мають втрат.

Виконання системного аналізу електромагнітних процесів у модуляційному напівпровідниковому перетворювачі (НПП) з багатозонним регулюванням вихідної напруги з електромеханічним навантаженням, в якості якого розглянуто ДПС з послідовним збудженням, 3 урахуванням таких ознак системного підходу до аналізу [4], як цілісність, декомпозиційність, мета системи та вплив під час іï руху зовнішніх і внутрішніх факторів.

Вихідну напругу НПП знаходимо, як

$$
\begin{gathered}
u_{\mathrm{H}}(t)=\frac{1}{k_{\mathrm{T}}} \sum_{n=1}^{N} \sum_{i=1}^{3} u_{1}(i, t) \\
\psi(n, N, t) \psi_{\mathrm{BB}}(t),
\end{gathered}
$$

де $u_{1}(i, t)$ - миттєві значення вхідних фазних напруг мережі живлення; $\psi_{\mathrm{B}}(i, t)-$ функції прямокутного синуса, що співпадають за часом 3 положенням відповідних фазних напруг мережі; $n=1,2,3, N$ - номери зон регулювання вихідної напруги; $\psi(n, N, t)$ - множина еквівалентних модулюючих впливів $i-\mathrm{x}$ інверторів $C M ; \psi_{\mathrm{BB}}(t)$ - функція прямокутного синуса, що співпадає за часом з положенням вихідної

(C) В. В. Михайленко, С. А. Абдулаєв, В. В. Ернст, В. В. Чупак, 2015 
напруги $u_{2}(t)$ ланки високої частоти НПП; $k_{\mathrm{T}}$ - коефіцієнт трансформації вихідних трансформаторів $C M$.

ДПС, що задає вихідний струм НПП, описується системою алгебраїчних рівнянь [4], яка подає миттєві значення струму кола якоря та його кутової швидкості з урахуванням пускового режиму у вигляді

$$
\left(\begin{array}{c}
i_{\mathrm{H}_{k+1}}(t) \\
n_{k+1}(t)
\end{array}\right)=\left(\begin{array}{c}
i_{\mathrm{H}_{k}}(t)+\frac{\left.2\left(c(t)-\varepsilon_{\mathrm{ch}}\right)\right)}{a_{1}}-\frac{2 \varepsilon_{a}}{a_{1}} i_{\mathrm{H}_{k}}(t)- \\
-\frac{2}{a_{1}} n_{k}(t) i_{\mathrm{H}_{k}}(t)-\frac{2}{a_{1} a_{3}} i_{\mathrm{H}_{k}}^{3}(t) ; \\
n_{k}(t)+\frac{\left.4\left(c(t)-\varepsilon_{\mathrm{ch}}\right)\right) i_{\mathrm{H}_{k}}(t)}{a_{1} a_{3}}- \\
-\frac{2 \varepsilon_{\mathrm{M}}}{a_{3}} n_{k}(t)+\frac{2}{a_{3}} i_{\hat{1}_{k}}^{2}(t)- \\
-\frac{2}{a_{1} a_{3}} i_{\mathrm{H}_{k}}^{2}(t) n_{k}(t)-\frac{2 \varepsilon_{\mathrm{M} 0}}{a_{3}},
\end{array}\right)
$$

де $i_{\mathrm{H}_{k+1}}(t), n_{k}(t), n_{k+1}(t)$ - струм якоря та кутова швидкість обертання ДПС на $k$-ому та в $k+1$-ому інтервалі відповідно; $\varepsilon_{\mathrm{ch}}, \varepsilon_{a}-$ відносні падіння напруги на щітках і обмотці якоря; $\varepsilon_{\mathrm{M} 0}-$ відносні моменти опору на валу; $c(t)=\frac{u_{\mathrm{H}}(t)}{E}-$ відносне значення напруги на якорі; $u_{\mathrm{H}}(t)$ та $E$ - миттєві значення вихідної напруги НПП та проти ЕРС відповідно; $a_{1}=\varepsilon_{a}+\frac{2 T_{a b}}{\Delta t}, \quad a_{3}=\varepsilon_{\mathrm{M}}+\frac{2 T_{\mathrm{M}}}{\Delta t} ; T_{a b}$ та $T_{\mathrm{M}}-$ електромагнітна та механічна постійні часу двигуна; $\Delta t$ - інтервали часу, за якими виконуються розрахунки процесів.

Система (2) вирішується за допомогою методу припасовування 3 попереднім записом початкових умов при $t=0$ та припущеннями відносно лінійної залежності моменту опору на валу двигуна від швидкості обертання [3] і лінеаризованої кривої намагнічування.

Діаграми струмів кола якоря ДПС для випадку п’ятизонного регулювання вихідної напруги НПП наведені на рис. 2. Крива 1 відображає струм кола якоря в процесі пуску ДПС під дією максимальної величини напруги
(3), а крива 2 - струм кола якоря в процесі пуску ДПС під дією напруги (3) з п'ятизонним широтно-імпульсним регулюванням (ШІР) за лінійним законом.

Вихідний струм $i_{2}(t)$ знаходимо 3 співвідношення

$$
i_{2}(t)=i_{\mathrm{H}_{k}}(t) \psi_{\mathrm{BB}}(t) .
$$

Вхідні струми $i_{1}(n, i, t)$ знаходимо з виразу

$$
i_{1}(n, i, t)=\frac{i_{2}(t) \psi_{\mathrm{B}}(i, t) \psi(n, N, t)}{k_{\mathrm{T}}} .
$$

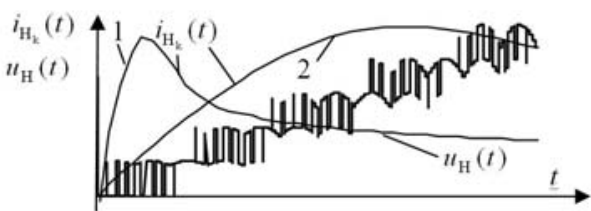

Рис. 2. Діаграми струмів кола якоря ДПС

Fig. 2. Current diagrams of armature circle in $\mathrm{CCM}$

\section{Результати}

Для визначення струмів $i-\mathrm{x}$ фаз мережі у всьому діапазоні регулювання вихідної напруги НПП підсумуємо вхідні струми IBH, що беруть участь у процесі регулювання вихідної напруги в кожній $з i-$ й фазі. Загальний вираз для струмів $i-\mathrm{x}$ фаз мережі подамо у вигляді

$$
i_{1}(i, t)=i_{1}(1, i, t)+i_{1}(2, i, t)+\ldots+i_{1}(N, i, t),
$$

де $i_{1}(1, i, t), i_{1}(2, i, t), i_{1}(N, i, t)$ - вхідні струми інверторів $i-$ х фаз на інтервалах першої, другої, та $N$-ї зони регулювання.

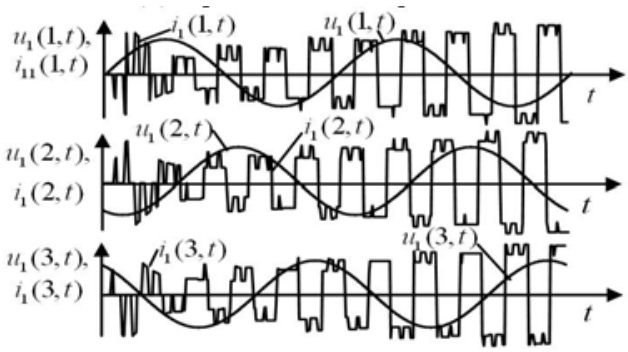

Рис. 3. Діаграми вхідних струмів $i$-х фаз мережі в координатах фазних напруг

Fig. 3. Diagrams of $i$-x phases incoming current in the net of delta voltage coordinates 
Діаграми вхідних струмів та напруг, побудовані за (5), наведені на рис. 3.

\section{Наукова новизна та практична значимість}

Створено нові схемотехнічні рішення напівпровідникових комутаторів 3 високочастотним широтно-імпульсним регулюванням їх вихідної напруги при зміні параметрів навантаження в широких межах, які дозволили підвищити швидкодію електротехнологічних систем.

\section{Висновки}

Таким чином у роботі було виконано аналіз електромагнітних процесів в електричних колах 3 напівпровідниковими комутаторами. Використовуючи метод багатопараметричних модулюючих функцій, було знайдено струм і напругу навантаження, а також вхідні струми перетворювача. Узагальнюючі функції багатопараметричного виду ефективні і для інших перетворювачів модуляційного типу.

\section{СПИСОК ВИКОРИСТАНИХ ДЖЕРЕЛ}

1. Афанасов, А. М. Определение рациональных режимов взаимного нагружения тяговых двигателей электроподвижного состава магистрального и промышленного транспорта // А. М. Афанасов // Наука та прогрес трансп. Вісн. Дніпропетр. нац. ун-ту залізн. трансп. 2014. - № 4 (52). - С. 67-74.

2. Забарило, Д. А. Особенности расчета силового трансформатора повышенной частоты / Д. А. Забарило // Наука та прогрес трансп. Вісн. Дніпропетр. нац. ун-ту залізн. трансп. 2013. - № 3 (45). - С. 29-35.

3. Каменєв, О. Ю. Проблематика підходів до дослідження безпеки використання енергетичних систем керування на залізничному транспорті / О. Ю. Каменєв // Наука та прогрес трансп. Вісн. Дніпропетр. нац. ун-ту залізн. трансп. - 2013. - № 2 (44). - С. 7-16.

4. Макаренко, М. П. Аналіз електромагнітних процесів у модуляційному напівпровідниковому перетворювачі напруги 3 електромеханічним навантаженням / М. П. Макаренко, В. В. Михайленко // Техн. електродинаміка. Силова електроніка та енергоефективність. 2003. - Ч. 3. - C. 21-24.
5. Макаренко, М. П. Аналіз електромагнітних процесів у перетворювачах з багатозонним регулюванням вихідної напруги функціями багатопараметричного виду / М. П. Макаренко, В. В. Михайленко // Техн. електродинаміка. Силова електроніка та енергоефективність. 2002. - Ч. 1. - С. 19-22.

6. Макаренко, М. П. Деякі аспекти комп'ютерного аналізу напівпровідникових перетворювачів електроенергії 3 багаторозгалуженими структурами / М. П. Макаренко, В. В. Михайленко // Техн. електродинаміка. Силова електроніка та енергоефективність. 2004. - Ч. 1. - С. 112-115.

7. Макаренко, М. П. Системний аналіз електромагнітних процесів у напів-провідникових перетворювачах електроенергії модуляційного типу : моногр. / М. П. Макаренко, В. І. Сенько, М. М. Юрченко. - Київ : Ін-т електродинаміки НАН України, 2005. - 241 с.

8. Макаренко, Н. П. Анализ и моделирование электромагнитных процессов в силовых преобразовательных устройствах методом модулирующих функций / Н. П. Макаренко // Техн. електродинаміка. Системи електроживлення електротехн. установок і комплексів. - Темат. вип. - 1999. - С. 44-47.

9. Макаренко, Н. П. Математическая модель процесса формирования выходных напряжений преобразователей частоты / Н. П. Макаренко, Г. Абарка // Электроника и связь. - 1999. № 6, T. 2. - С. 60-64.

10. Макаренко, Н. П. Экологические вопросы сетей вторичных систем электроснабжения промышленных предприятий / Н. П. Макаренко, Г. Абарка, Е. В. Небрат // Вісн. УБЕНТЗ. 1999. - № 5. - C. 7-12.

11. Hojabri, H. A Generalized Technique of Modeling, Analisis, and Control of a Matrix Converter Using SVD / H. Hojabri, H. Mokhtari, L. Chang // IEEE Trans. On Industrial Electronics. 2011. - Vol. 58, № 3. - P. 949-959. doi: 10.1109/TIE.2010.2048836.

12. Hojabri, H. Reactive Power Control Permanentmagnet Synchronous Wind Generator with Matrix Converter / H. Hojabri, H. Mokhtari, L. Chang // IEEE Trans. On Power Delivery. - 2013. - Vol. 28, № 2. - P. 575-584. doi: 10.1109/TPWRD.2012.2229721.

13. Range of the linear modulation in matrix converters / L. Zarri, M. Mengoni, A. Toni, J. O. Ojo // IEEE Trans. On Power Electronics. - 2014. - Vol. 29, № 6. - P. 3166-3178. doi: 10.1109/tpel.2013.2274285. 


\title{
В. В. МИХАЙЛЕНКО ${ }^{*}$, С. А. АБДУЛАЕВ ${ }^{2}$, В. В. ЭРНСТ ${ }^{3}$, В. В. ЧУПАК ${ }^{4}$
}

\author{
${ }^{1 *}$ Каф. «Теоретическая электротехника», Национальный технический университет Украины «Киевский политехнический \\ институт», пр-т Победы, 37, Киев, Украина, 03056, тел./факс + 38 (098) 317 93 74, эл. почта VladislavMihailenko@i.ua, \\ ORCID 0000-0002-5945-7502 \\ ${ }^{2}$ Каф. «Электрические сети и системы», Национальный технический университет Украины «Киевский политехнический \\ институт», пр-т Победы, 37, Киев, Украина, 03056, тел./факс + 38 (098) 985 26 00, эл. почта seryk15abdulaev@rambler.ru, \\ ORCID 0000-0001-8939-1471 \\ ${ }^{3}$ Каф. «Электрические сети и системы», Национальный технический университет Украины «Киевский политехнический \\ институт», пр-т Победы, 37, Киев, Украина, 03056, тел./факс + 38 (050) 901 13 94, эл. почта vasilyernst@mail.ru, \\ ORCID 0000-0002-2922-0918 \\ ${ }^{4}$ Каф. «Технологии машиностроения», Национальный технический университет Украины «Киевский политехнический \\ институт», пр-т Победы, 37, Киев, Украина, 03056, тел./факс + 38 (097) 86806 35, эл. почта viktorchupak@ukr.net, \\ ORCID 0000-0002-7103-6364

\section{МАТЕМАТИЧЕСКАЯ МОДЕЛЬ ПОЛУПРОВОДНИКОВОГО ПРЕОБРАЗОВАТЕЛЯ С ПЯТИЗОННЫМ РЕГУЛИРОВАНИЕМ ВЫХОДНОГО НАПРЯЖЕНИЯ И ЭЛЕКТРОМЕХАНИЧЕСКОЙ НАГРУЗКОЙ}

Цель. Работа направлена на исследование электромагнитных процессов в электрических цепях с полупроводниковыми коммутаторами. Необходимо разработать новые математические модели, определения функций и алгоритмических уравнений для анализа установившихся и переходных процессов в электрических цепях переменной структуры. Также предусмотрено исследовать математические модели с полупроводниковыми коммутаторами и звеньями, в которых возникают синусоидные, постоянные и импульсные напряжения. Методика. Для достижения поставленной цели была создана математическая модель полупроводникового преобразователя с электромеханической нагрузкой. Показано, что появление нелинейных элементов сильно усложняет задачи расчета и исследования возникающих в цепях электромагнитных процессов. Наибольшие осложнения появляются в цепях переменной структуры, в которых возникают синусоидные, постоянные и импульсные токи под действием соответствующих напряжений. Результаты. Разработаны новые математические модели электромагнитных процессов в трехфазных электрических цепях полупроводниковых преобразователей с многоканальным зонным регулированием фазных напряжений (без учета потерь в полупроводниковых коммутаторах) для быстрой оценки влияния параметров нагрузки на уровень и форму выходного напряжения. Научная новизна. Разработан метод многопараметрических функций, которые входят в алгоритмические уравнения анализа установившихся и переходных процессов в разветвленных электрических цепях с полупроводниковыми коммутаторами и реактивными элементами, в направлении учета особенностей использования фазных напряжений сети электропитания. Обосновано, что использование метода многопараметрических модулирующих функций в электрических цепях переменной структуры является целесообразным, если в их звеньях есть не более трех независимых реактивных элементов. Разработана новая математическая модель устоявшихся и переходных процессов в электрических цепях полупроводниковых преобразователей модуляционного типа с многоканальным зонным использованием фазных напряжений трехфазной сети питания. При этом потери электроэнергии в коммутаторах не учитывались. Такая математическая модель была разработана для быстрой оценки влияния параметров нагрузки на характеристики регулируемых синусоидальных и постоянных напряжений. Практическая значимость. Созданы новые схемотехнические решения полупроводниковых коммутаторов с высокочастотным широтноимпульсным регулированием выходного напряжения при изменении параметров нагрузки в широких пределах. Это позволило повысить быстродействие электротехнологических систем. Разработаны методики повышения скорости регулирования и определения энергоэффективных режимных параметров полупроводниковых коммутаторов электротехнологических систем. Разработаны новые методики анализа установившихся и переходных процессов в электрических цепях полупроводниковых преобразователей модуляционного типа с постоянными выходными напряжениями и с различными видами модулирующих влияний.

Ключевые слова: электромагнитные процессы; выходное напряжение; выходной ток; двигатель постоянного тока; метод многопараметрических модулирующих функций 


\begin{abstract}
V. V. MIKHAILENKO ${ }^{*}$, S. A. ABDULAIEV ${ }^{2}$, V. V. ERNST ${ }^{3}$, V. V. CHUPAK ${ }^{4}$
${ }^{1 *}$ Dep. «Theoretical Electrical Engineers», National Technical University of Ukraine «Kyiv Polytechnic Institute», Peremoga Av., 37, Kyiv , Ukraine, 03056, tel./fax + 38 (098) 31793 74, e-mail VladislavMihailenko@i.ua, ORCID 0000-0002-5945-7502 ${ }^{2}$ Dep. «Electric Networks and Systems», National Technical University of Ukraine «Kyiv Polytechnic Institute», Peremoga Av., 37, Kyiv , Ukraine, 03056, tel./fax + 38 (098) 98526 00, e-mail seryk15abdulaev@rambler.ru, ORCID 0000-0001-8939-1471 ${ }^{3}$ Dep. «Electric Networks and Systems», National Technical University of Ukraine «Kyiv Polytechnic Institute», Peremoga Av., 37, Kyiv , Ukraine, 03056, тел./факс + 38 (050) 901 13 94, e-mail vasilyernst@mail.ru, ORCID 0000-0002-2922-0918

${ }^{4}$ Dep. «Technologies of Machine Building», National Technical University of Ukraine «Kyiv Polytechnic Institute», Peremoga

Av., 37, Kyiv , Ukraine, 03056, tel./fax + 38 (097) 86806 35, e-mail viktorchupak@ukr.net, ORCID 0000-0002-7103-6364
\end{abstract}

\title{
MATHEMATICAL MODEL OF SEMICONDUCTOR CONVERTER WITH FIVE-ZONE REGULATION OF THE OUTPUT VOLTAGE AND ELECTROMECHANICAL LOAD
}

Purpose. This work is directed on study of the electromagnetic processes in electric circuits with semiconductor commutators. It is necessary to develop the new mathematical models of functions determination and algorithmic equations for analysis of formed and transition processes in electric circuits of the variable structure. To research the mathematical models with semiconductor commutators and sections, in which sine, constant and pulsed voltages appear. Methodology. The mathematical model of the semiconductor converter with electromechanical load was created for achievement the purpose in view. It is shown that appearance of nonlinear element complicates powerfully the problems of the calculation and studies appearing in circuits of the electromagnetic processes. The most complications appear in circuits of the variable structure, in which sine, constant and pulsed current arise under the action of appropriete voltages. Findings. The new mathematical models of the electromagnetic processes were designed in three-phase electric circuit of the semiconductor converters with multiserver zoned regulation of phase voltages (without losses in semiconductor commutators) for quick estimation the load parameters influence on level and form of the output voltage. Originality. The method of multi-parameter functions was developed. The last are included in algorithmic equations for analysis of formed and transition processes in network with semiconductor commutators and reactive elements, in the considerations direction of phase to neutral voltages usage in the power circuit. It is motivated that use of the multi-parameter modulating functions method in electric circuit of variable structures is expedient if in their sections there are not more than three independent reactive elements. The new mathematical model of formed and transition processes in electric circuits of the semiconductor converters, modulation type with multiserver zoned use of phase to neutral voltages in three-phase network of the power supply was developed. At that energy loss in commutators were not taken into account. Such mathematical model was created for quick estimation the influence of parameters load on controlled features of sine and constant voltages. Practical value. New scheme technical solutions of semiconductor commutators with high-frequency impulse relative time regulation of output voltage when change parameters load in a wide range were created. It has allowed raising the speed of the electro technological systems. The increase in speed methods of regulation and determinations the energy efficient mode parameters of semiconductor commutators of the electro technological systems were developed. The new methods of analyzes of formed and transition processes in electric circuits of semiconductor converters, modulation type with constant output voltages and with miscellaneous types of modulating influence.

Keywords: electromagnetic processes; output voltage; output current; the engine of the direct current; the method of multi-parameter modulating functions

\section{REFERENCES}

1. Afanasov A.M. Opredeleniye ratsionalnykh rezhimov vzaimnogo nagruzheniya tyagovykh dvigateley elektropodvizhnogo sostava magistralnogo i promyshlennogo transporta [Rational modes determination of traction motors loading-back for electric rolling stock in mainline and industrial transport]. Nauka ta prohres transportu. Visnyk Dnipropetrovskoho natsionalnoho universytetu zaliznychnoho transportu - Science and Transport Progress. Bulletin of Dnipropetrovsk National University of Railway Transport, 2014, no. 4 (52), pp. 67-74.

2. Zabarilo D.A. Osobennosti rascheta silovogo transformatora povyshennoy chastoty [Features of the high frequency power transformer calculation]. Nauka ta prohres transportu. Visnyk Dnipropetrovskoho natsionalnoho universytetu zaliznychnoho transportu - Science and Transport Progress. Bulletin of Dnipropetrovsk National University of Railway Transport, 2013, no. 3 (45), pp. 29-35. 
3. Kameniev O.Yu. Problematyka pidkhodiv do doslidzhennia bezpeky vykorystannia enerhetychnykh system keruvannia na zaliznychnomu transporti [Problematics of approaches to research of the use safety of ergatic control systems on railway transport]. Nauka ta prohres transportu. Visnyk Dnipropetrovskoho natsionalnoho universytetu zaliznychnoho transportu - Science and Transport Progress. Bulletin of Dnipropetrovsk National University of Railway Transport, 2013, no. 2 (44), pp. 7-16.

4. Makarenko M.P., Mykhailenko V.V. Analiz elektromahnitnykh protsesiv u moduliatsiinomu napivprovidnykovomu peretvoriuvachi napruhy $\mathrm{z}$ elektromekhanichnym navantazhenniam [The analysis of electromagnetic processes in the modulation semiconductor voltage converter with electromechanical loads]. Tekhnichna elektrodynamika. Sylova elektronika ta enerhoefektyvnist - Technical electrodynamics. Power Electronics and Energy Efficiency, 2003, part 3, pp. 21-24.

5. Makarenko M.P., Mykhailenko V.V. Analiz elektromahnitnykh protsesiv u peretvoriuvachakh $\mathrm{z}$ bahatozonnym rehuliuvanniam vykhidnoi napruhy funktsiiamy bahatoparametrychnoho vydu [The analysis of electromagnetic processes in converters with multi-zone adjustment of output voltage by multi-parameter type functions]. Tekhnichna elektrodynamika. Sylova elektronika ta enerhoefektyvnis - Technical Electrodynamics. Power Electronics and Energy Efficiency, 2002, part 1, pp. 19-22.

6. Makarenko M.P., Mykhailenko V.V. Deiaki aspekty kompiuternoho analizu napivprovidnykovykh peretvoriuvachiv elektroenerhii z bahatorozghaluzhenymy strukturamy [Some aspects of computer analysis of semiconductor power converters with branched structures]. Tekhnichna elektrodynamika. Sylova elektronika ta enerhoefektyvnist - Technical electrodynamics. Power Electronics and Energy Efficiency, 2004, part 1, pp. 112-115.

7. Makarenko M.P., Senko V.I., Yurchenko M.M. Systemnyi analiz elektromahnitnykh protsesiv u napivprovidnykovykh peretvoriuvachakh elektroenerhii moduliatsiinoho typu [System analysis of electromagnetic processes in the semiconductor power converters of modulation type]. Kyiv, Instytut elektrodynamiky NAN Ukrainy Publ., 2005. 241 p.

8. Makarenko N.P. Analiz i modelirovaniye elektromagnitnykh protsessov v silovykh preobrazovatelnykh ustroystvakh metodom moduliruyushchikh funktsiy [Analysis and modeling of electromagnetic processes in the power conversion devices by method of modulating functions]. Tekhnichna elektrodynamika. Systemy elektrozhyvlennia elektrotekhnichnykh ustanovok i kompleksiv - Technical electrodynamics. Power Systems of Electrical Installations and Complexes, 1999, special issue, pp. 44-47.

9. Makarenko, N.P., Abarka G. Matematicheskaya model protsessa formirovaniya vykhodnykh napryazheniy preobrazovateley chastoty [Mathematical model of the process of generating output voltages of the inverters]. Elektronika i svyaz - Electronics and Communication, 1999, no. 6, vol. 2, pp. 60-64.

10. Makarenko N.P., Abarka G., Nebrat Ye.V. Ekologicheskiye voprosy setey vtorichnykh sistem elektrosnabzheniya promyshlennykh predpriyatiy [Environmental issues in networks of the secondary power supply systems of industrial enterprises]. Visnyk Ukrainskoho budynku ekonomichnykh ta naukovotekhnichnykh znan [Bulletin of Ukrainian house of economic, scientific and technical knowledges], 1999 , no. 5, pp. 7-12.

11. Hojabri H.A., Mokhtari H., Chang L. Generalized Technique of Modeling, Analisis, and Control of a Matrix Converter Using SVD. IEEE Trans. On Industrial Electronics, 2011, vol. 58, no. 3, pp. 949-959. doi: 10.1109/TIE.2010.2048836.

12. Hojabri H., Mokhtari H., Chang L. Reactive Power Control Permanent-magnet Synchronous Wind Generator with Matrix Converter. IEEE Trans. On Power Delivery, 2013, vol. 28, no. 2, pp. 575-584. doi: 10.1109/TPWRD.2012.2229721.

13. Zarri L., Mengoni M., Toni A., Ojo J.O. Range of the linear modulation in matrix converters. IEEE Trans. On Power Electronics, 2014, vol. 29, no. 6, pp. 3166-3178. doi: 10.1109/tpel.2013.2274285 .

Стаття рекомендована до публікації д.т.н., проф. В. І. Сеньком (Україна); д.т.н., проф. А. М. Афанасовим (Украіна)

Надійшла до редколегії 04.11.2014

Прийнята до друку 25.02.2015 